\title{
Long-term Clinical Outcome and MIBI SPECT Parameters in Percutaneous Coronary Interventions
}

\author{
M. de Mulder • F. M. van der Zant • P. Knaapen • \\ J. H. Cornel • V. A. W. M. Umans
}

Published online: 8 February 2011

(C) The Author(s) 2011. This article is published with open access at Springerlink.com

\begin{abstract}
Background and Aim Primary percutaneous coronary intervention (PCI) is the preferred treatment option for acute myocardial infarction (MI). Off-site PCI reduces time-totreatment, which could potentially lead to enhanced clinical outcomes. Therefore, we investigated whether off-site PCI improves 5-year clinical outcomes compared with on-site PCI and whether this is related to in-hospital ${ }^{99 \mathrm{~m}} \mathrm{Tc}$-sestamibi single photon emission computed tomography (MIBI SPECT) parameters.

Methods We describe the 5-year follow-up for a combined endpoint of death or re-infarction in 128 patients with acute MI who were randomly assigned to undergo primary PCI at the off-site centre $(n=68)$ or to transferral to an on-site centre $(n=60)$. Three days after PCI, MIBI SPECT was performed to estimate infarct size. A multivariate Cox regression model was created to study the relation between MIBI SPECT parameters and long-term clinical outcomes. Results After a mean follow-up of $5.8 \pm 1.1$ years, 25 events occurred. Off-site PCI significantly reduced door-to-balloon time compared with on-site PCI $(94 \pm 54$ versus $125 \pm$ $59 \mathrm{~min}, p=0.003)$. However, infarct size $(17 \pm 15$ versus
\end{abstract}

The questions can be answered after the article has been published in print. You have to $\log$ in to: www.cvoi.nl.

M. de Mulder · J. H. Cornel • V. A. W. M. Umans $(\bowtie)$

Department of Cardiology, Medical Centre Alkmaar,

1815 JD Alkmaar, the Netherlands

e-mail: v.umans@mca.nl

F. M. van der Zant

Department of Nuclear Medicine, Medical Centre Alkmaar,

Alkmaar, the Netherlands

\section{P. Knaapen}

Department of Cardiology, VU University Medical Centre,

Amsterdam, the Netherlands
$14 \pm 12 \%, p=0.34)$ and 5 -year death or infarct rate $(21 \%$ versus $18 \%, p=0.75$ ) were comparable between treatment centres. With multivariate analysis, only Killip class $\geq 2$ and $\mathrm{Q}$ wave MI, but not scintigraphic data, predicted long-term clinical outcomes.

Conclusion Off-site PCI reduced door-to-balloon time with a comparable 5-year death or infarct rate. Parameters from resting MIBI SPECT on day 3 after MI did not predict long-term clinical outcomes.

Keywords Primary angioplasty $\cdot$ Myocardial infarction $\cdot{ }^{99 \mathrm{~m}} \mathrm{Tc}$-sestamibi SPECT $\cdot 5$-Year clinical outcome

\section{Introduction}

Primary percutaneous coronary intervention (PCI) is widely accepted as the preferred reperfusion strategy to reduce infarct size in patients with acute ST-segment elevation myocardial infarction (STEMI) [1]. Trials comparing PCI in STEMI patients presented to large community hospitals without onsite cardiac surgical backup (off-site) versus PCI in a tertiary interventional centre (on-site) have demonstrated that off-site PCI is feasible and results in comparable short-term clinical outcome [2,3]. Treatment in off-site centres results in a significant reduction in time-to-treatment, which could potentially lead to a reduction in infarct size by more timely salvage of acutely jeopardised ischaemic myocardium [4-6]. In that respect, off-site PCI without transfer delay in STEMI patients might even prove to be superior in limiting infarct size $[7,8]$.

We extended our earlier findings [9] and investigated whether off-site PCI improves 5-year clinical outcomes compared with on-site PCI and if this is related to in- 
hospital ${ }^{99 \mathrm{~m}} \mathrm{Tc}$-sestamibi single photon emission computed tomography (SPECT) parameters.

\section{Methods}

\section{Patients}

This study describes the 5-year follow-up of STEMI patients who, in a previous study, were randomly assigned to primary PCI at the centre of presentation in a community hospital (offsite, $n=103$ ) or to transferral to a remote tertiary centre with surgical backup facilities (on-site, $n=96$ ) [6]. The in-hospital outcomes in relation to ${ }^{99 \mathrm{~m}} \mathrm{Tc}$-sestamibi SPECT parameters in 128 patients were described previously [9]. STEMI patients who presented within $6 \mathrm{~h}$ after the onset of symptoms, who were able to give informed consent and did not require mechanical ventilatory assistance were eligible for randomisation. Upon arrival at the cardiac care unit and prior to randomisation, all patients were immediately treated with heparin, aspirin, nitroglycerin, and abciximab, unless contraindicated. Standard treatment after the PCI procedure included clopidogrel, $\beta$-blockers, aspirin, ACE inhibitors, and statins, unless contraindicated. The protocol was approved by the review board or ethics committee of each hospital.

Of the original consecutive patient population $(n=199)$, 128 patients consented to ${ }^{99 \mathrm{~m}}$ Tc-sestamibi SPECT imaging 3 days after the cardiac event. Failure to undergo ${ }^{99 \mathrm{~m}} \mathrm{Tc}-$ sestamibi SPECT was due to early death (5), emergency CABG (1), previous myocardial infarction (MI; 11), unable or unwilling to provide consent (42), no PCI was performed and the absence of MI (4).

\section{Scintigraphy}

Rest gated myocardial perfusion images were acquired approximately $1 \mathrm{~h}$ after an intravenous injection of $700 \mathrm{MBq}{ }^{99 \mathrm{~m}}$ Tc-sestamibi using SPECT. A dual-head camera system, equipped with low-energy high-resolution collimators, was used for myocardial imaging (Millennium VG; GE Healthcare). Images were acquired in a $64 \times 64$ matrix with an acquisition time of $30 \mathrm{~s}$ per image. The SPECT images were gated with eight frames per cardiac cycle, and the RR time acceptance was set at $20 \%$. Transaxial slices were reconstructed via back projection with a ramp filter, followed by a butterworth filter. Using commercially available software, polar maps were created of the relative distribution of tracer uptake throughout the entire left ventricle (LV). Each polar map was normalised to its individual maximum, and the defect size was defined as $<50 \%$ uptake area of the polar map and was subsequently expressed as a percentage of the LV.
Follow-up

Information on survival status was obtained in all patients in June 2009. Digital hospital records were reviewed for all-cause mortality and enzymatically confirmed myocardial re-infarction (re-MI), i.e. typical chest pain plus creatine kinase-MB (CK-MB) or troponin I above the upper limit of normal, i.e. $>16 \mathrm{U} / 1$ and $>0.45 \mu \mathrm{g} / \mathrm{l}$, respectively.

\section{Statistical Analysis}

Data are expressed as mean \pm standard deviation (SD). Frequencies were compared using Fisher's exact test and Student's $t$ test, and continuous variables were compared using the independent $t$ test. Comparison of multiple datasets was performed using ANOVA, and specific differences were identified by a Student's $t$ test corrected for multiple comparisons with the Bonferroni adjustment.

The incidence of the combined endpoint over time was evaluated according to the Kaplan-Meier method, and differences between groups of patients were analysed with the log-rank test. Univariate analysis of the combined endpoint over time for baseline and ${ }^{99 \mathrm{~m}}$ Tc-sestamibi SPECT parameters was performed using Cox proportional hazard regression. Variables with a $p$ value $<0.5$ in univariate analysis were included in the multivariable model so that no (measured) confounders were missed, using the enter method. All analyses were performed using SPSS 14 (SPSS Inc., Chicago, Illinois). A $p$ value $<0.05$ was considered significant.

\section{Results}

The study cohort consisted of 128 patients, 93 (73\%) were men, and the mean age was $62 \pm 12$ SD years. Baseline characteristics and risk profile were comparable between the 60 patients randomised to on-site and 68 patients randomised to off-site PCI (Table 1). Mean follow-up was 5.8 years $\pm 1.1 \mathrm{SD}$. In this time frame, 15 re-MIs were documented, and ten patients died. Kaplan-Meier analysis demonstrated that there was no difference in long-term outcomes and centre of randomisation, log rank 0.715 (Fig. 1).

Time to Treatment and Centre of Randomisation

The time lines revealed no difference in mean time from onset of symptoms to presentation at the clinic between groups. However, with a reduction of $31 \mathrm{~min}$, the doorto-balloon time was significantly shorter in the off-site centre, although this did not result in a significant reduction in pain onset time-to-treatment. Neither did 
Table 1 Patient characteristics

CVD cardiovascular disease, $P C I$ percutaneous coronary intervention, $C A B G$ coronary artery bypass grafting, TIMI thrombolysis in myocardial infarction

\begin{tabular}{lccc}
\hline & On-site $(n=60)$ & Off-site $(n=68)$ & $p$ \\
\hline Age (years) & $64 \pm 11$ & $61 \pm 12$ & 0.62 \\
Men & $44(73 \%)$ & $49(72 \%)$ & 0.87 \\
Diabetes mellitus & $4(7 \%)$ & $2(3 \%)$ & 0.32 \\
Smoker & $24(40 \%)$ & $33(49 \%)$ & 0.59 \\
Hypertension & $15(25 \%)$ & $20(29 \%)$ & 0.58 \\
Family history of CVD & $27(45 \%)$ & $28(41 \%)$ & 0.66 \\
Previous PCI & $2(3 \%)$ & $2(3 \%)$ & 0.90 \\
Previous CABG & $3(5 \%)$ & $2(3 \%)$ & 0.55 \\
Killip class $>1$ & $1(1 \%)$ & $1(2 \%)$ & 0.92 \\
Summed ST deviation (mm) & $15 \pm 12$ & $17 \pm 9$ & 0.27 \\
Anterior myocardial infarction & $23(38 \%)$ & $26(38 \%)$ & 0.99 \\
Q wave & $32(53 \%)$ & $42(62 \%)$ & 0.24 \\
Multi (>1) vessel disease & $23(38 \%)$ & $28(41 \%)$ & 0.74 \\
TIMI flow pre PCI <2 & $38(67 \%)$ & $51(75 \%)$ & 0.31 \\
TIMI flow post PCI <2 & $1(2 \%)$ & $2(3 \%)$ & 0.67 \\
Symptoms-to-admission (min) & $158 \pm 131$ & $163 \pm 201$ & 0.87 \\
Symptoms-to-balloon (min) & $286 \pm 146$ & $257 \pm 211$ & 0.38 \\
Symptoms-to-arrival (min) & $158 \pm 131$ & $163 \pm 201$ & 0.87 \\
Door-to-balloon (min) & $125 \pm 59$ & $257 \pm 211$ & 0.003 \\
Time-to-treatment (min) & $286 \pm 146$ & & 0.39 \\
\hline
\end{tabular}

this reduction of door-to-balloon time result in an enzymatically smaller infarct size in off-site-treated patients, peak CK-MB 204 vs. $161 \mathrm{U} / 1 ; p$ value, 0.11 (Table 2). In univariate and multivariate analyses, this was further confirmed as none of the time line variables had a significant relation with long-term clinical outcomes.

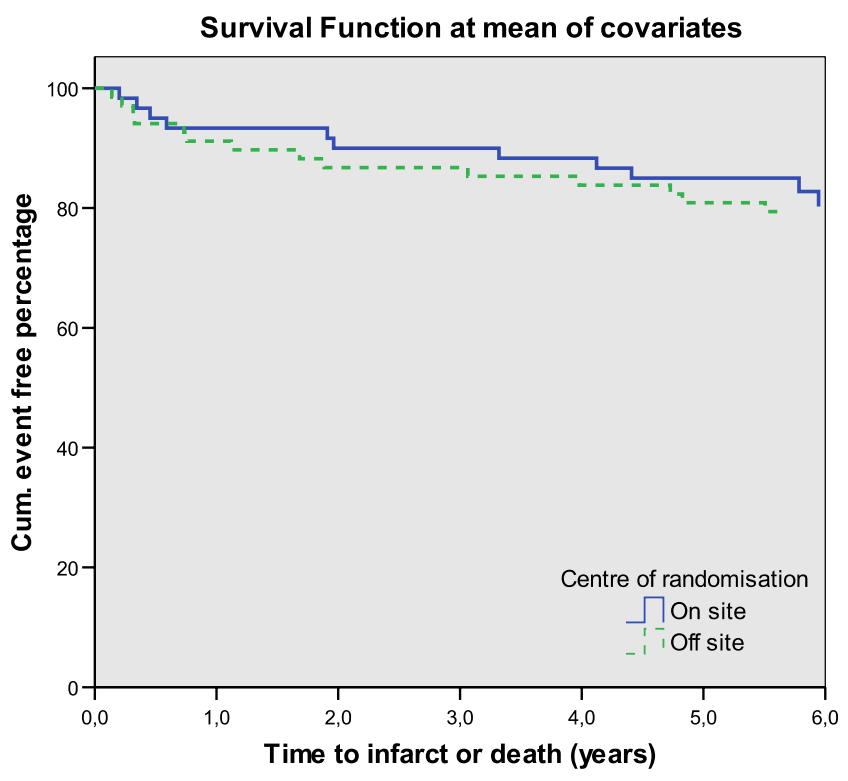

Fig. 1 Difference in long-term follow-up between centres for the combined endpoint of either death or re-infarction; log rank, 0.715
Scintigraphic Data and Centre of Randomisation

Various scintigraphic variables were analysed, but most were comparable between on- and off-site PCI. However, the summed thickening score (STS) was smaller in patients randomised to on-site treatment, $14 \pm 12$ versus $17 \pm 15 \mathrm{SD}$; $p$ value, 0.028 (Table 2).

Table 2 Comparison of centres regarding MIBI SPECT data and 5-year clinical outcomes

\begin{tabular}{lccl}
\hline & On-site $(n=60)$ & Off-site $(n=68)$ & $p$ \\
\hline Death or infarct & $11(18 \%)$ & $14(21 \%)$ & 0.75 \\
LVESV (ml) & $58 \pm 26$ & $65 \pm 31$ & 0.17 \\
LVEDV (ml) & $118 \pm 36$ & $124 \pm 38$ & 0.34 \\
LVEF (\%) & $52 \pm 12$ & $50 \pm 11$ & 0.06 \\
Infarct extent (\%) & $14 \pm 12$ & $17 \pm 15$ & 0.34 \\
SRS & $11 \pm 9.6$ & $12 \pm 12$ & 0.33 \\
SMS & $19 \pm 13$ & $24 \pm 20$ & 0.06 \\
STS & $14 \pm 12$ & $17 \pm 15$ & 0.028 \\
Peak CK & $1611 \pm 1838$ & $1894 \pm 1609$ & 0.35 \\
Peak CK-MB (U/l) & $161 \pm 136$ & $204 \pm 160$ & 0.11 \\
\hline
\end{tabular}

Continuous data are presented as mean values \pm standard deviation. Dichotomous data are presented as numbers and percentages

SPECT single photon emission computed tomography, LVESV left ventricular end-systolic volume, $L V E D V$ left ventricular end-diastolic volume, $L V E F$ left ventricular ejection fraction, SRS summed rest score, $S M S$ summed motion score, STS summed thickening score, $C K$ creatine kinase 


\section{Scintigraphic Data and 5-Year Clinical Outcome}

We investigated if parameters from a ${ }^{99 \mathrm{~m}} \mathrm{Tc}$-sestamibi SPECT on day 3 were related to the combined endpoint of death or re-MI at 5-year follow-up. However, in univariate and multivariate Cox regression analyses, none of the assessed scintigraphic parameters were related to this combined endpoint. Only a higher Killip class and Q wave infarction were related (Table 3).

\section{Discussion}

The results indicate that despite a 31-minute reduction of door-to-balloon time, scintigraphic parameters and 5-year clinical outcome are not considerably affected by performing off-site PCI. Additionally, in our series, off- site PCI is equally safe compared with on-site PCI. However, the reduction in door-to-balloon time did not result in improved 5-year clinical outcomes with off-site PCI.

\section{Scintigraphic Data and Long-Term Clinical Outcome}

Scintigraphic parameters did not predict 5-year clinical outcomes. This is in contrast to the results of Spinelli et al. who found that dysfunctional but viable myocardium with preserved systolic thickening was the strongest predictor of cardiovascular risk [10]. However, the infarct size in their study was quite small, while larger infarcts, i.e. $>12 \%$ of LV myocardial mass correlate to mortality [11]. Clinical factors that independently predicted 5-year clinical outcomes in our series were a higher Killip class and Q-wave myocardial infarction.

Table 3 Univariate and multivariate analyses for the long-term combined endpoint (death/re-MI)

\begin{tabular}{|c|c|c|c|}
\hline & Crude hazard ratio and $95 \% \mathrm{CI}$ & Multivariate adjusted hazard ratio and $95 \% \mathrm{CI}$ & $P$ value \\
\hline Off-site centre & $1.2(0.53-2.6)$ & $1.3(0.56-3.2)$ & 0.51 \\
\hline Age (years) & $1.03(0.99-1.06)$ & $1.03(0.99-1.1)$ & 0.14 \\
\hline Men & $1.0(0.42-2.4)$ & - & \\
\hline Diabetes mellitus & $3.2(0.97-11)$ & $2.5(0.63-9.7)$ & 0.20 \\
\hline Smoker & $1.3(0.72-2.2)$ & $1.3(0.74-2.3)$ & 0.36 \\
\hline Hypertension & $1.3(0.54-2.9)$ & - & \\
\hline Family history of CVD & $0.60(0.26-1.4)$ & $0.76(0.31-1.8)$ & 0.54 \\
\hline Previous PCI & $0.05(0-600)$ & - & \\
\hline Previous CABG & $1.1(0.15-8.3)$ & - & \\
\hline Killip class $>1$ & $2.8(0.38-21)$ & $25.1(2.0-315)$ & 0.013 \\
\hline Summed ST deviation (mm) & $1.03(0.72-1.5)$ & - & \\
\hline Anterior myocardial infarction & $1.3(0.60-2.9)$ & $1.4(0.49-4.0)$ & 0.54 \\
\hline Q wave & $3.1(1.2-8.4)$ & $3.4(1.02-11.2)$ & 0.046 \\
\hline Multi-vessel disease $(>1)$ & $1.1(0.49-2.4)$ & - & \\
\hline TIMI flow pre PCI $<2$ & $1.2(0.51-2.8)$ & - & \\
\hline TIMI flow post PCI $<2$ & $0.46(0.06-3.4)$ & $0.75(0.08-7.3)$ & 0.80 \\
\hline Symptoms-to-admission (h) & $1.06(0.96-1.16)$ & $0.94(0.61-1.5)$ & 0.79 \\
\hline Door-to-balloon (h) & $1.01(0.68-1.5)$ & - & \\
\hline Time-to-treatment (h) & $1.05(0.96-1.15)$ & $1.09(0.71-1.7)$ & 0.69 \\
\hline LVESV (10 ml) & $1.02(0.90-1.2)$ & - & \\
\hline LVEDV $(10 \mathrm{ml})$ & $1.01(0.91-1.1)$ & - & \\
\hline LVEF (\%) & $1.0(0.97-1.03)$ & - & \\
\hline Infarct extent $(\%)$ & $1.02(0.99-1.04)$ & $1.0(0.82-1.2)$ & 0.97 \\
\hline SRS & $1.02(0.99-1.05)$ & $1.03(0.80-1.3)$ & 0.83 \\
\hline SMS & $1.01(0.99-1.03)$ & $1.03(0.95-1.1)$ & 0.50 \\
\hline STS & $1.01(0.99-1.03)$ & $0.95(0.86-1.1)$ & 0.35 \\
\hline
\end{tabular}

Variables with a $p$ value $<0.5$ in univariate analysis and all scintigraphic variables were included in the multivariable model

$M I$ myocardial infarction, $L V E S V$ left ventricular end-systolic volume, $L V E D V$ left ventricular end-diastolic volume, $L V E F$ left ventricular ejection fraction, SRS summed rest score, SMS summed motion score, STS summed thickening score 
On-Site Versus Off-Site PCI: Influence on Clinical and Scintigraphic Parameters

In spite of a reduced door-to-balloon time, off-site PCI did not result in a significantly different infarct size or long-term clinical outcomes, although the STS was smaller in on-site PCI. However, the 31-min reduction in door-to-balloon time in off-site PCI was relatively short. Myocardial salvage is particularly pronounced within the first $2 \mathrm{~h}$ of infarction and levels off in the ensuing hours [12]. Given the average time-to-treatment of $4.5 \mathrm{~h}$, this may have obscured a potential benefit, particularly as few patients (10\%) were treated within this early timeframe.

Door-to-Balloon Time: Influence on Clinical and Scintigraphic Parameters

Earlier large studies demonstrated that time-to-treatment is important in salvaging acutely jeopardised myocardium when performing a primary PCI $[5,13]$. However, in our study, a relationship between timing of reperfusion and infarct size or 5-year clinical outcome could not be established. This is similar to results from smaller studies that provided conflicting results with the larger studies $[6,14]$.

\section{Limitations}

The number of investigated patients was relatively small and may explain why the impact of time on infarct size or long-term clinical outcome was not apparent. In addition, this study was performed in an area with a good infrastructure and relatively small inter-hospital transfer distances. In a more remote area, differences might actually become apparent.

The ${ }^{99 \mathrm{~m}}$ Tc-sestamibi SPECT might have been too early, since early cardiac remodelling after the acute phase takes several weeks before a final equilibrium has been reached [15]. Therefore, it might have been more appropriate to perform this scan at a later stage, e.g. 6 weeks after the event.

\section{Conclusion}

After a mean follow-up of 5.8 years, long-term clinical outcomes and scintigraphic parameters were not affected by performing off-site PCI, despite a 31-min reduction of doorto-balloon time. Parameters from rest gated ${ }^{99 \mathrm{~m}} \mathrm{Tc}$-sestamibi SPECT on day 3 after MI did not predict long-term clinical outcomes.
Open Access This article is distributed under the terms of the Creative Commons Attribution Noncommercial License which permits any noncommercial use, distribution, and reproduction in any medium, provided the original author(s) and source are credited.

\section{References}

1. Keeley EC, Hillis LD. Primary PCI for myocardial infarction with ST-segment elevation. N Engl J Med. 2007;356:47-54.

2. Peels HO, de Swart H, Ploeg TV, et al. Percutaneous coronary intervention with off-site cardiac surgery backup for acute myocardial infarction as a strategy to reduce door-to-balloon time. Am J Cardiol. 2007;100:1353-8.

3. Wharton Jr TP, Grines LL, Turco MA, et al. Primary angioplasty in acute myocardial infarction at hospitals with no surgery on-site (the PAMI-No SOS study) versus transfer to surgical centers for primary angioplasty. J Am Coll Cardiol. 2004;43:1943-50.

4. Thiele H, Kappl MJ, Linke A, et al. Influence of time-to-treatment, TIMI-flow grades, and ST-segment resolution on infarct size and infarct transmurality as assessed by delayed enhancement magnetic resonance imaging. Eur Heart J. 2007;28:1433-9.

5. De Luca G, Suryapranata H, Ottervanger JP, et al. Time delay to treatment and mortality in primary angioplasty for acute myocardial infarction: every minute of delay counts. Circulation. 2004;109:12235.

6. McNamara RL, Wang Y, Herrin J, et al. Effect of door-to-balloon time on mortality in patients with ST-segment elevation myocardial infarction. J Am Coll Cardiol. 2006;47:2180-6.

7. Wharton Jr TP. Should patients with acute myocardial infraction be transferred to a tertiary center for primary angioplasty or receive it at qualified hospitals in community? The case for community hospital angioplasty. Circulation. 2005;112:3509-20.

8. Nallamothu BK, Bradley EH, Krumholz HM. Time to treatment in primary percutaneous coronary intervention. $N$ Engl $\mathrm{J}$ Med. 2007;357:1631-8.

9. Knaapen P, de Mulder M, van der Zant FM, et al. Infarct size in primary angioplasty without on-site cardiac surgical backup versus transferal to a tertiary center: a single photon emission computed tomography study. Eur J Nucl Med Mol Imaging. 2009;36:237-43.

10. Spinelli L, Petretta M, Acampa W, et al. Prognostic value of combined assessment of regional left ventricular function and myocardial perfusion by dobutamine and rest gated SPECT in patients with uncomplicated acute myocardial infarction. J Nucl Med. 2003;44:1023-9.

11. Miller TD, Christian TF, Hopfenspirger MR, et al. Infarct size after acute myocardial infarction measured by quantitative tomographic $99 \mathrm{mTc}$ sestamibi imaging predicts subsequent mortality. Circulation. 1995;92:334-41.

12. Brodie BR, Stuckey TD, Wall TC, et al. Importance of time to reperfusion for 30-day and late survival and recovery of left ventricular function after primary angioplasty for acute myocardial infarction. J Am Coll Cardiol. 1998;32:1312-9.

13. Brodie BR, Stone GW, Cox DA, et al. Impact of treatment delays on outcomes of primary percutaneous coronary intervention for acute myocardial infarction: analysis from the CADILLAC trial. Am Heart J. 2006;151:1231-8.

14. Cannon CP, Gibson CM, Lambrew CT, et al. Relationship of symptom-onset-to-balloon time and door-to-balloon time with mortality in patients undergoing angioplasty for acute myocardial infarction. JAMA. 2000;283:2941-7.

15. Opie LH, Commerford PJ, Gersh BJ, et al. Controversies in ventricular remodelling. Lancet. 2006;367:356-67. 